\title{
(-) astemex \\ latrogenic propagation of coronary dissection during diagnostic coronary angiography: an uncommon but important procedural consideration
}

\author{
Chirag K. Desai, Udit Bhatnagar, Adam Stys, Orvar Jonsson
}

Cardiovascular Disease, University of South Dakota Sanford School of Medicine, Sioux Falls, South Dakota, USA

\section{Correspondence to} Dr Chirag K. Desai, chirag.ks.desai@gmail.com

Accepted 28 November 2017

\begin{abstract}
SUMMARY
Spontaneous coronary artery dissection is an uncommon cause of acute myocardial infarction in the general population but is relatively more common in the peripartum period. Regardless of clinical setting, the management strategy is individualised, ranging from conservative to invasive. We report a case of peripartum myocardial infarction due to spontaneous coronary dissection that propagated during diagnostic angiography and ultimately required emergent bypass surgery.
\end{abstract}

\section{BACKGROUND}

Spontaneous coronary artery dissection is an incompletely understood and uncommon cause of myocardial infarction. It is however more common in the peripartum state, with potentially disastrous consequences without prompt action. When the condition is identified on coronary angiography, care must be taken during the procedure to minimise the risk of progressive coronary dissection and subsequent vessel closure. We review a case of coronary dissection in a peripartum patient that despite conservative radiocontrast autoinjector settings was complicated by rapid vessel occlusion and could not be treated percutaneously.

\section{CASE PRESENTATION}

A 35-year-old woman presented with centrally located chest heaviness radiating to arms, shoulder blades and upper back after waking up. The pain was not affected by activity or position, but was associated with nausea and dizziness. She had similar, less severe episodes of discomfort over the prior 2 days lasting not more than 30 minutes;

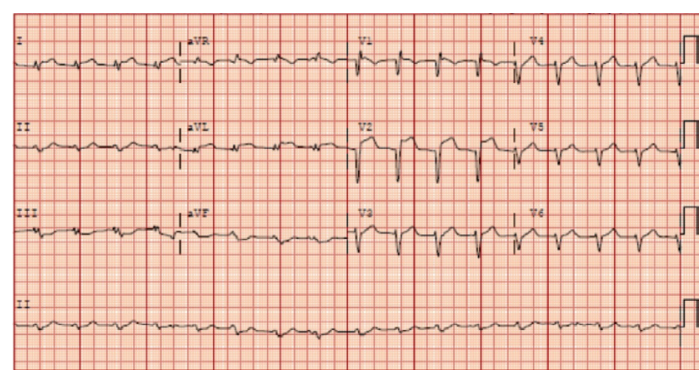

Figure 1 Presenting ECG suggesting anteroseptal STelevation myocardial infarction. however, the chest pain this time was prolonged and more severe. The patient had previously suffered three spontaneous abortions but was now 2 weeks post partum after the delivery of healthy twins. She was herself previously healthy and took no medications. Family history was unremarkable for cardiac risk. Her cardiovascular physical examination was normal.

The initial ECG is shown in figure 1. Her chest discomfort had resolved in the emergency department, and her initial serum troponin level was within normal limits. CT was negative for pulmonary embolism and aortic dissection. Due to high-risk clinical history and ECG findings, she underwent emergent coronary angiography.

During contrast injection of the left coronary system, the patient redeveloped severe chest pain, deep precordial ST depressions on telemetry, bradycardia and hypotension.

\section{INVESTIGATIONS}

- Serum troponin I at presentation: $0.04 \mathrm{ng} / \mathrm{mL}$ (upper limit of normal $=0.04 \mathrm{ng} / \mathrm{mL}$ ).

- Serum troponin I at 2 hours: $25.26 \mathrm{ng} / \mathrm{mL}$.

- Peak troponin I at 9 hours: $56.5 \mathrm{ng} / \mathrm{mL}$.

- Total cholesterol: $98 \mathrm{mg} / \mathrm{dL}$.

- High-density lipoprotein cholesterol: $26 \mathrm{mg} /$ dL.

- Low-density lipoprotein cholesterol: $56 \mathrm{mg} / \mathrm{dL}$.

\section{DIFFERENTIAL DIAGNOSIS}

- Coronary arterial spasm.

- Catheter-induced coronary dissection.

- Aortic dissection.

- Worsening ischaemia due to contrast injection and severe underlying coronary stenosis.

\section{TREATMENT}

Angiography showed left main coronary artery (LM) into left anterior descending artery (LAD) occlusion with dye-staining and angiographic features suggestive of dissection (figure 2). The patient required emergent intubation for fulminant respiratory failure, placement of an Impella ventricular assist device and a temporary transvenous pacemaker. While preparations were made for emergent bypass surgery, a guidewire was placed in the LAD, and balloon angioplasty was used to restore flow, revealing an ulcerated distal LM into LAD dissection, as well as dissection spiralling 


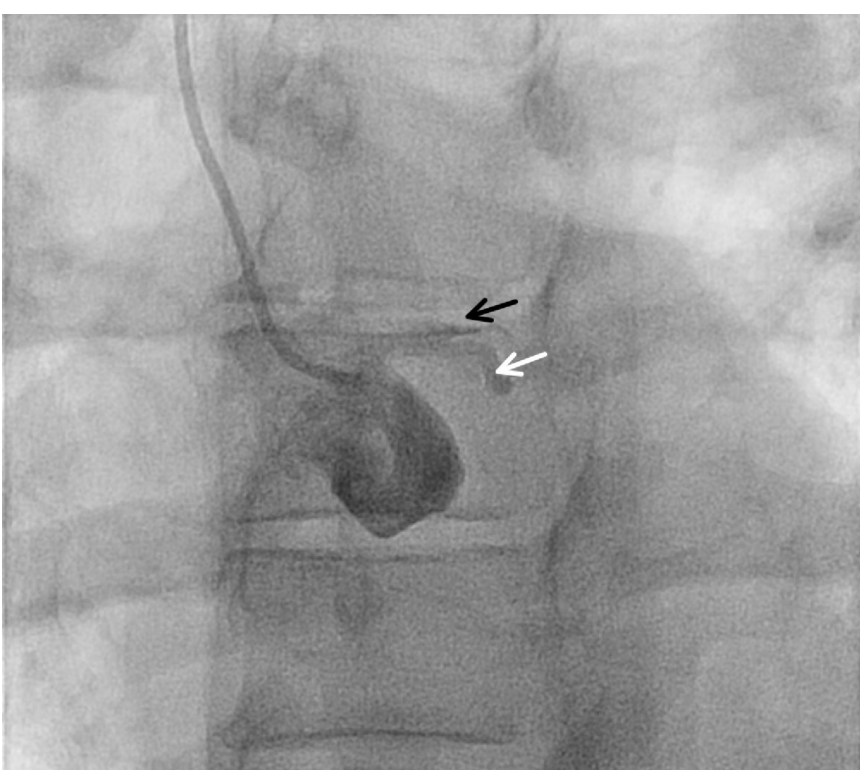

Figure 2 Initial images on diagnostic coronary angiography suggesting left anterior descending (black arrow) and circumflex artery (white arrow) occlusion, camera angle Left Angerior Oblique $26^{\circ}$, Cranial $2^{\circ}$.

distally into the circumflex artery (figure 3). The right coronary artery was patent. The patient was taken emergently to the operating room for placement of a left internal mammary artery graft to the LAD and a saphenous vein graft to the first obtuse marginal branch.

\section{OUTCOME AND FOLLOW-UP}

The patient recovered well postoperatively and was discharged uneventfully. At 6-month follow-up, she was doing well and reported no issues.

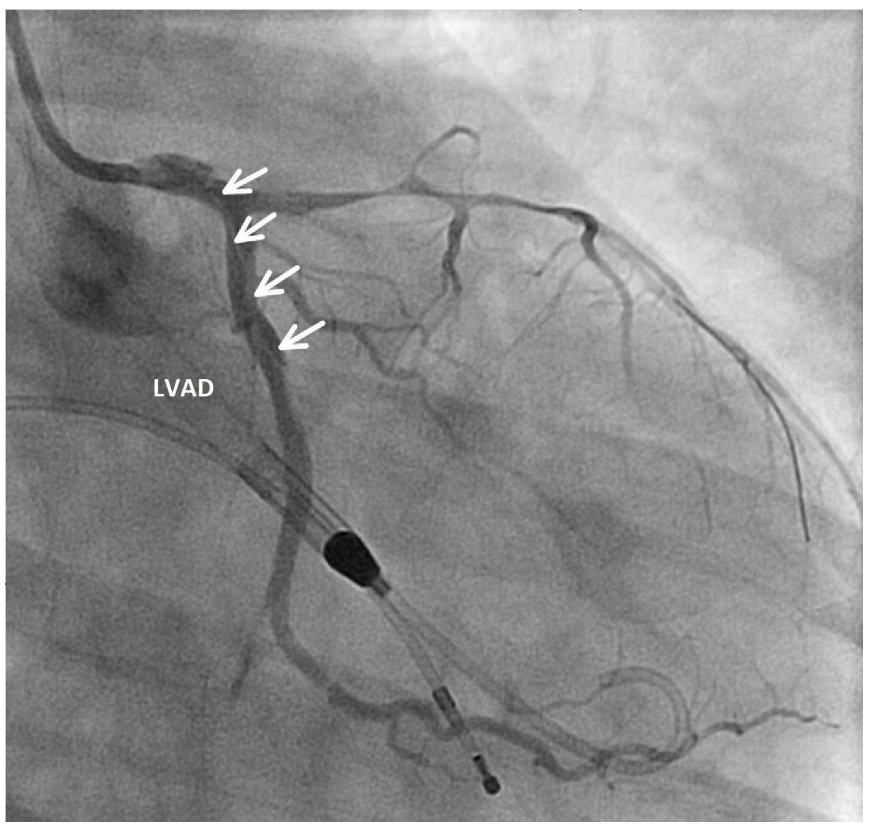

Figure 3 Angiographic view showing ulcerated left main artery dissection with propagation down left anterior descending and spiral dissection down circumflex artery (arrows), in-line left ventricular assist device (LVAD), camera angle Right Anterior Oblique $9^{\circ}$, Caudal $29^{\circ}$.

\section{DISCUSSION}

Coronary dissection is a very important diagnostic consideration for all peripartum acute coronary syndrome (ACS) presentations. The incidence of peripartum myocardial infarction is thought to be low, estimated at 6.2 per 100000 pregnancies in one population-based study. ${ }^{1}$ In another series, coronary artery dissection was the cause of $43 \%$ of cases of peripartum myocardial infarction, ${ }^{2}$ highlighting this condition's disproportionately higher incidence in patients who are currently or recently pregnant. The typical risk factor for this complication during iatrogenic cases-particularly pre-existing coronary disease-is not generally present in spontaneous peripartum cases. ${ }^{3}$ In the latter, variations in level of sex hormones are postulated to influence arterial structure ${ }^{4}$ while other groups have demonstrated a possible vasculitic component, ${ }^{5}$ perhaps due to changes in peripartum immune function. While the exact mechanism remains unclear, there appears to be a general consensus on an association of pregnancy-associated changes in the pathogenesis of dissection.

Regardless of the mechanism, when the index of suspicion is high that coronary dissection may occur or has already occurred, efforts must be made by the operator to limit the iatrogenic contribution to this problem. In general, iatrogenic causes of de novo dissection include catheter tip or guidewire trauma, vigorous contrast injection and angioplasty balloon overinflation. $^{6-8}$ In the present case, the procedure was performed via radial access, which requires usually more complex catheter manipulation than the femoral route, potentially increasing the risk of inadvertent catheter trauma or deep vessel intubation. Similarly, force of contrast injection is an important procedural consideration, especially in pre-existing coronary dissection cases undergoing angiography. We use an automated contrast injection system, which could, in theory, help reduce risk of dissection or propagation by allowing the operator precise control over injection parameters (peak pressure, rate of pressure rise and volume). Current studies seem to suggest reduced contrast exposure and access site complications with the use of automatic contrast injectors, ${ }^{9}{ }^{10}$ but further study and consensus guidelines would be helpful to determine what programmed settings of automatic injectors are most likely to reduce the risk of iatrogenic dissection and/or propagation.

Spontaneous coronary dissection remains an uncommon cause of myocardial infarction, and the optimal approach to management is a subject of ongoing study due to the low frequency of this condition and conflicting data. One of the larger retrospective studies of patients presenting with acute coronary syndrome due to spontaneous dissection found that the majority of patients could be safely managed conservatively in the absence of clinical instability or poor culprit vessel flow while percutaneous intervention (PCI) overall did not improve long-term vessel patency and was associated with a high complication rate and need for emergent bypass surgery. ${ }^{11}$ In another single-centre study, the authors also found poor procedural success rates with PCI and recurrent ischaemic events regardless of the treatment approach. ${ }^{12}$ Given the theoretical advantages of restoring normal vasomotion and endothelial function, a number of groups have reported successful use of bioresorbable vascular scaffolds (BVS) in patients presenting with spontaneous coronary dissection who were treated with PCI. ${ }^{13-15}$ While this seems a promising future strategy, the relatively bulky first-generation BVS systems preclude their use in tortuous or small vessel segments at present. The choice of medications used-dual antiplatelet therapy in the setting of infarction, beta blockers and ACE inhibitors-is based 
Learning points

Spontaneous coronary dissection is an important diagnostic consideration for myocardial infarction, particularly in younger patients and peripartum presentations.

- Except in the setting of clinical instability or poor culprit vessel flow, spontaneous coronary dissection is often treated conservatively.

- Trauma from catheter manipulation and vigorous contrast injection can in theory both initiate and propagate coronary dissection, resulting in clinical decompensation.

- It remains to be seen how the use of bioresorbable vascular scaffolds and programmable contrast injection systems can improve care in patients presenting with a high likelihood of coronary dissection.

on their indications for atherosclerotic ACS and must take into account both current pregnancy and lactation status. The use of thrombolytics has also not been systematically studied, but is controversial due to the theoretical possibility for dissection/ haematoma extension. ${ }^{12}$

In summary, utmost care must be taken by the operator to minimise the risk of propagation during angiography in the setting of ACS when the risk of spontaneous coronary dissection is high. The role of newer technologies such as automated contrast injection systems in reducing this risk remains to be determined. The choice of therapy must be individualised based on clinical stability to ensure best clinical outcome for both mother and child.

Contributors CKD drafted and revised the manuscript. UB, AS and OJ assisted with all subsequent and final manuscript revisions.

Competing interests None declared.

Patient consent Obtained.

Provenance and peer review Not commissioned; externally peer reviewed.

Open Access This is an Open Access article distributed in accordance with the Creative Commons Attribution Non Commercial (CC BY-NC 4.0) license, which permits others to distribute, remix, adapt, build upon this work non-commercially, and license their derivative works on different terms, provided the original work is properly cited and the use is non-commercial. See: http://creativecommons.org/ licenses/by-nc/4.0/

(c) BMJ Publishing Group Ltd (unless otherwise stated in the text of the article) 2017. All rights reserved. No commercial use is permitted unless otherwise expressly granted.

\section{REFERENCES}

1 James $\mathrm{AH}$, Jamison MG, Biswas MS, et al. Acute myocardial infarction in pregnancy: a United States population-based study. Circulation 2006;113:1564-71.

2 Elkayam U, Jalnapurkar S, Barakkat MN, et al. Pregnancy-associated acute myocardial infarction: a review of contemporary experience in 150 cases between 2006 and 2011. Circulation 2014;129:1695-702.

3 Celik SK, Sagcan A, Altintig A, et al. Primary spontaneous coronary artery dissections in atherosclerotic patients. Report of nine cases with review of the pertinent literature. Eur J Cardiothorac Surg 2001;20:573-6.

4 Heefner WA. Dissecting hematoma of the coronary artery. A possible complication of oral contraceptive therapy. JAMA 1973;223:550-1.

5 Carreon CK, Esposito MJ. Eosinophilic coronary monoarteritis. Arch Pathol Lab Med 2014;138:979-81.

6 Pérez-Castellano N, García-Fernández MA, García EJ, et al. Dissection of the aortic sinus of valsalva complicating coronary catheterization: cause, mechanism, evolution, and management. Cathet Cardiovasc Diagn 1998;43:273-9.

7 Park IW, Min PK, Cho DK, et al. Successful endovascular treatment of iatrogenic coronary artery dissection extending into the entire ascending aorta. Can J Cardiol 2008;24:857-9.

8 Sohrabi B, Kazemi B, Aslanabadi N. Percutaneous treatment of catheter-induced dissection of the right coronary artery and adjacent aortic wall. J Invasive Cardiol 2007;19:E199-202.

9 Anne G, Gruberg L, Huber A, et al. Traditional versus automated injection contrast system in diagnostic and percutaneous coronary interventional procedures: comparison of the contrast volume delivered. J Invasive Cardiol 2004;16:360-2.

10 Godley RW, Joshi K, Breall JA. A comparison of the use of traditional hand injection versus automated contrast injectors during cardiac catheterization. J Invasive Cardiol 2012;24:628-30.

11 Tweet MS, Eleid MF, Best PJ, et al. Spontaneous coronary artery dissection: revascularization versus conservative therapy. Circ Cardiovasc Interv 2014;7:777-86.

12 Havakuk O, Goland S, Mehra A, et al. Pregnancy and the risk of spontaneous coronary artery dissection: an analysis of 120 contemporary cases. Circ Cardiovasc Interv 2017; 10.

13 Mahmood MM, Austin D. IVUS and OCT guided primary percutaneous coronary intervention for spontaneous coronary artery dissection with bioresorbable vascular scaffolds. Cardiovasc Revasc Med 2017;18:53-7.

14 Basavarajaiah S, Naganuma T, Qadir M. Use of bioresorbable vascular scaffold in acute dissection: insights from optical coherence tomography. JACC Cardiovasc Interv 2016;9:e5-9.

15 lelasi A, Cortese B, Tarantini G, et al. Sealing spontaneous coronary artery dissection with bioresorbable vascular scaffold implantation: Data from the prospective 'Registro Absorb Italiano' (RAI Registry). Int J Cardiol 2016;212:44-6.

Copyright 2017 BMJ Publishing Group. All rights reserved. For permission to reuse any of this content visit

http://group.bmj.com/group/rights-licensing/permissions.

BMJ Case Report Fellows may re-use this article for personal use and teaching without any further permission.

Become a Fellow of BMJ Case Reports today and you can:

- Submit as many cases as you like

- Enjoy fast sympathetic peer review and rapid publication of accepted articles

- Access all the published articles

- Re-use any of the published material for personal use and teaching without further permission

For information on Institutional Fellowships contact consortiasales@bmjgroup.com

Visit casereports.bmj.com for more articles like this and to become a Fellow 